\title{
Comparative Expression Profiling of Nicotiana benthamiana Leaves Systemically Infected with Three Fruit Tree Viruses
}

\author{
Christopher Dardick \\ United States Department of Agriculture-Agricultural Research Service, Appalachian Fruit Research Station, Kearneysville, \\ WV, U.S.A.
}

Submitted 30 January 2007. Accepted 14 March 2007.

\begin{abstract}
Plant viruses cause a wide array of disease symptoms and cytopathic effects. Although some of these changes are virus specific, many appear to be common even among diverse viruses. Currently, little is known about the underlying molecular determinants. To identify gene expression changes that are concomitant with virus symptoms, we performed comparative expression profiling experiments on Nicotiana benthamiana leaves infected with one of three different fruit tree viruses that produce distinct symptoms: Plum pox potyvirus (PPV; leaf distortion and mosaic), Tomato ringspot nepovirus (ToRSV; tissue necrosis and general chlorosis), and Prunus necrotic ringspot ilarvirus (PNRSV; subtle chlorotic mottling). The numbers of statistically significant genes identified were consistent with the severity of the observed symptoms: 1,082 (ToRSV), 744 (PPV), and 89 (PNRSV). In all, $56 \%$ of the gene expression changes found in PPV-infected leaves also were altered by ToRSV, $87 \%$ of which changed in the same direction. Both PPV- and ToRSV-infected leaves showed widespread repression of genes associated with plastid functions. PPV uniquely induced the expression of large numbers of cytosolic ribosomal genes whereas ToRSV repressed the expression of plastidic ribosomal genes. How these and other observed expression changes might be associated with symptom development are discussed.
\end{abstract}

Additional keywords: biotic stress, cell death, chloroplast, microarray.

Virus disease and ensuing crop failure results from a wide array of destructive symptoms. These often include plant stunting, changes in leaf or fruit morphology, tissue chlorosis, necrosis, and sometimes plant death. The development of virus symptoms is a complex phenomenon and varies with respect to the specific virus-host and even strain-host combination, plant developmental status at the time of infection, and envi-

Corresponding author: C. Dardick; E-mail: chris.dardick@ars.usda.gov

Nucleotide sequence data is available in the GenBank and TIGR databases. Accession numbers for all significant genes are provided in Table S1.

* The $\boldsymbol{e}$-Xtra logo stands for "electronic extra" and indicates Figures 1, 2, 5,6 and 7 appear in color online. Six supplementary tables also appear online.

This article is in the public domain and not copyrightable. It may be freely reprinted with customary crediting of the source. The American Phytopathological Society, 2007. ronmental conditions, including light and temperature (Matthews 1991). Moreover, they are often transient because plants can recover from an initial infection "shock" and symptoms later reappear in response to environmental changes or after seasonal plant dormancy. Although the physical and cellular changes associated with symptom development have been documented extensively over the past 100 years, the molecular causes are largely unknown. A detailed understanding of these interactions should lead to new and creative methods to control plant viruses.

Recently, a number of examples have emerged from the literature providing insight into some of the molecular mechanisms that contribute to symptom development. Padmanabhan and associates (2006) identified a host protein (IAA26/PAP1) in Arabidopsis that is sequestered from the nucleus by the Tobacco mosaic virus (TMV) replicase. Transgenic plants designed to mimic the sequestration of IAA26/PAP1 in the absence of virus show phenotypes similar to virus-infected plants (Padmanabhan et al. 2005, 2006). IAA26/PAP1 is a member of a family of transcription factors that control the expression of auxin-responsive genes. The geminivirus replication protein AL1 was found to interact with a host retinoblastoma protein (pRBR). A strain carrying an AL1 mutation that disrupted interactions with pRBR produced distinct symptoms and, unlike the wild type, was restricted to the vascular tissue (Kong et al. 2000). The rice dwarf virus capsid protein P2 associates with an ent-kaurene oxidase that plays a central role in gibberellin biosynthesis. Exogenous application of gibberellin blocked the dwarfing symptom (Zhu et al. 2005). In addition to direct interaction with host proteins, virus disruption of host miRNA regulation via virus-encoded silencing inhibitors also has been implicated as a potential cause of symptom development (Kasschau et al. 2003). Other indirect impacts also are likely to contribute to symptoms such as altered hormone regulation (Jameson and Clark 2002). Collectively, these examples indicate that plant viruses induce symptoms by interfering with multiple host developmental or metabolic signaling pathways.

Microarray technology has emerged as a powerful tool to evaluate changes in the expression of thousands of genes simultaneously. A number of microarray experiments have focused on virus-infected plants (Chen et al. 2002; Golem and Culver 2003; Huang et al. 2005; Marathe et al. 2004; Senthil et al. 2005; Trinks et al. 2005; Whitham et al. 2003). A majority of these studies have taken advantage of the model system Arabidopsis and have revealed a remarkable complexity in host responses to plant viruses that vary depending on the source of tissue, time postinfection, virus strain, and host. From these studies, a number of genes have been found to be 
commonly induced by plant viruses (Whitham et al. 2006). These are associated primarily with more general biotic and abiotic stress responses. Although it is assumed that genes associated with symptom development are represented within these expression data, identifying which genes and how they relate to symptoms remains a substantial hurdle. Making these analyses particularly problematic are difficulties comparing data across experiments that use different microarray platforms and experimental approaches, the biological complexity of virus-infected tissue composed of different cell types and disease states, as well as the large numbers of genes lacking known functions.

Comparative studies using related or unrelated viruses that cause both common and distinct symptoms in the same host plant offer opportunities to link changes in global gene expression to specific symptoms. This is based on the hypothesis that similar symptoms produced by different viruses or strains will share overlapping changes in global gene expression. Likewise, these changes should not be found in virus-host combinations which lack the associated symptoms. Although Arabidopsis has been widely used to study virus-host interactions and is susceptible to numerous viruses, it is not always ideal for comparative studies because some plant viruses infect only one or a few particular ecotypes or do not cause symptoms (Balasubramaniama et al. 2006; Dardick et al. 2000; Decroocq et al. 2006; Mahajan et al. 1998; Senthil et al. 2005; Simon et al. 1992). In these respects, Nicotiana benthamiana offers an attractive alternative for comparative gene expression studies. The Institute for Genomic Research (TIGR, Rockville MD, U.S.A.) potato cDNA array was used successfully by Senthill and colleagues to study gene expression changes in $N$. benthamiana that result from infection by negative-sense, enveloped RNA viruses (Rensink et al. 2005; Senthill et al. 2005). Here, this same system was used to study the impacts of positivesense stone fruit RNA viruses on host gene expression.
Unlike many other crops afflicted by bacterial or fungal pathogens, stone fruit production, including peach, plum, apricot, and cherry, primarily suffers from viral diseases. The most notorious and destructive disease is Sharka, caused by Plum pox potyvirus (PPV). PPV has long ravaged European fruit production and was first identified in the United States in 1999. Other economically important stone fruit viruses, including Tomato ringspot nepovirus (ToRSV) and Prunus necrotic ringspot ilarvirus (PNRSV), also cause significant losses to stone fruit production. PPV, ToRSV, and PNRSV are all single-stranded, positive-sense RNA viruses that infect many of the same hosts but differ in genome organization and particle morphology (Fig. 1). In this study, we sought to compare both symptoms and impacts on host gene expression by these viruses in $N$. benthamiana, with the goal of identifying both shared and virus-specific host transcriptional changes.

\section{RESULTS}

\section{PPV, ToRSV, and PNRSV produce distinct symptoms in $N$. benthamiana.}

N. benthamiana plants infected with PPV, ToRSV, or PNRSV were monitored for symptom development over a period of 4 weeks. Each virus produced distinct symptoms (Fig. 2). PPV symptoms were typical for potyviruses, including changes in leaf morphology and the appearance of mosaic chlorosis. In contrast, ToRSV caused severe yellowing in systemically infected leaves and systemic necrosis by 2 weeks postinoculation (PI). Following initial collapse of the primary stem, plants typically recovered by 4 weeks PI and remained chlorotic and stunted. Though virus could be detected in systemic leaves by enzyme-linked immunosorbent assay (data not shown), PNRSV induced little or no symptoms by 2 weeks PI and only subtle chlorotic mottling was observed at 4 weeks PI.
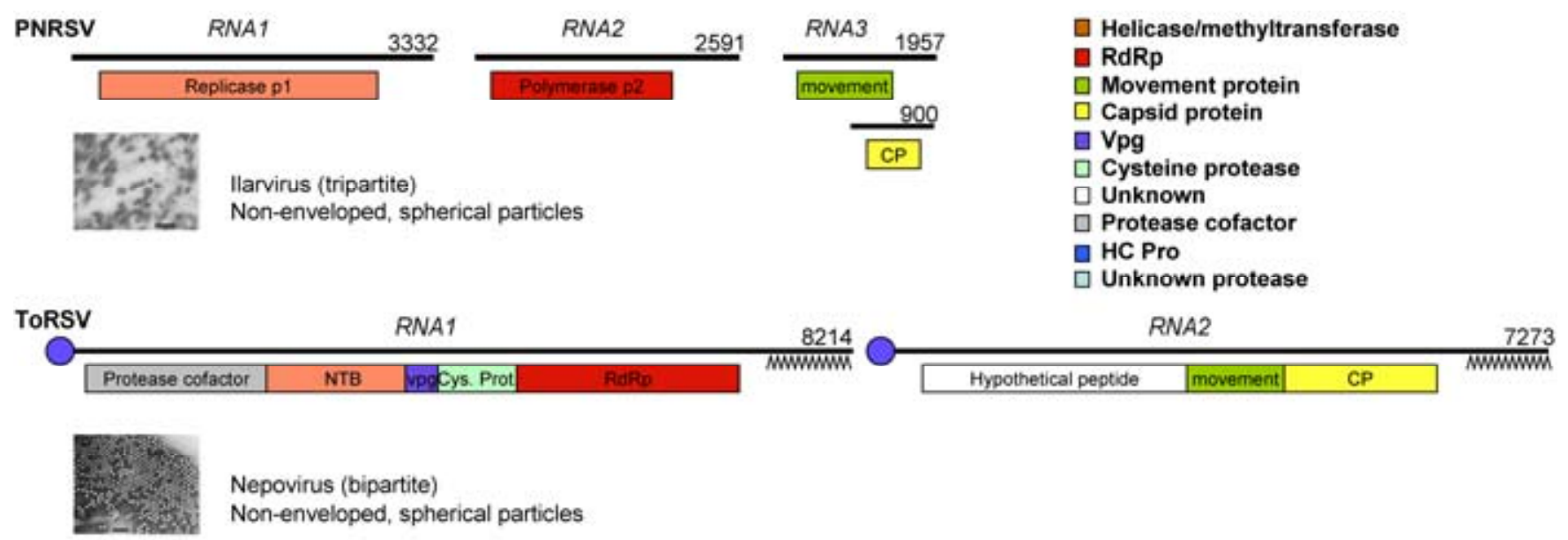

Nepovirus (bipartite)

Non-enveloped, spherical particles
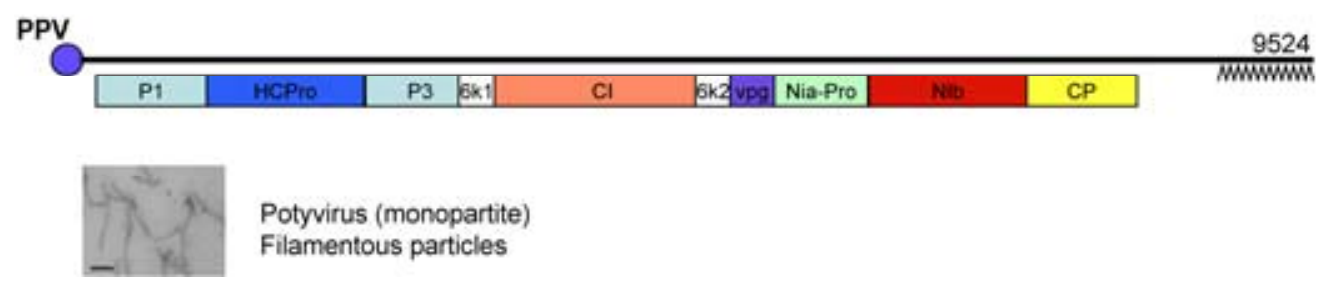

Potyvirus (monopartite)

Filamentous particles

Fig. 1. Genome organization of Prunus necrotic ringspot ilarvirus (PNRSV), Tomato ringspot nepovirus (ToRSV), and Plum pox potyvirus (PPV). Features, open reading frames and nucleotide length of each genome are shown. The PNRSV coat protein is encoded by a subgenomic RNA derived from RNA 3. Both PPV and ToRSV RNAs contain poly A tails and encode polyproteins (a single large polypeptide is cleaved by viral encoded proteases to produce functional viral proteins). The circles shown on the $5^{\prime}$ ends of ToRSV and PPV represent the viral encoded VPg cap required for translation. Electron microscope images of PNRSV and PPV virions are from C. Dardick and C. Murphy (unpublished research). The nepovirus image was kindly provided by Rothamsted Research. Copyright for this image is the property of Rothamsted Research. 


\section{Microarray experimental design.}

To compare expression profiles of the distinct disease states produced by these three viruses, upper noninoculated symptomatic leaves were harvested for RNA extraction after 2 weeks PI. Microarray hybridization experiments are outlined in Figure 3. A reference design was used in which labeled cDNA derived from each virus-infected sample was hybridized with labeled cDNA from the same mock-inoculated controls. This design allowed for direct comparisons between the expression profiles resulting from all three virus infections. To obtain robust and statistically accurate data, four biological replicates and four technical replicates (dye swaps) were used for all virus treatments and mock-inoculated controls. Each biological rep- licate consisted of 16 to 20 symptomatic leaves derived from four infected plants. The four plants were obtained from two sets of independent inoculations (two plants each) performed 8 weeks apart but maintained under the same conditions in the same growth chamber.

\section{Data analysis and rationale.}

Diseased tissue is biologically complex. Each infected leaf consists of multiple tissue types and symptomatic states (Havelda and Maule 2000). Virus infection typically is incomplete and only specific zones within the leaf contain high titers of virus. Virus-free tissue sometimes is observed as "green islands" which are resistant to subsequent virus infection due
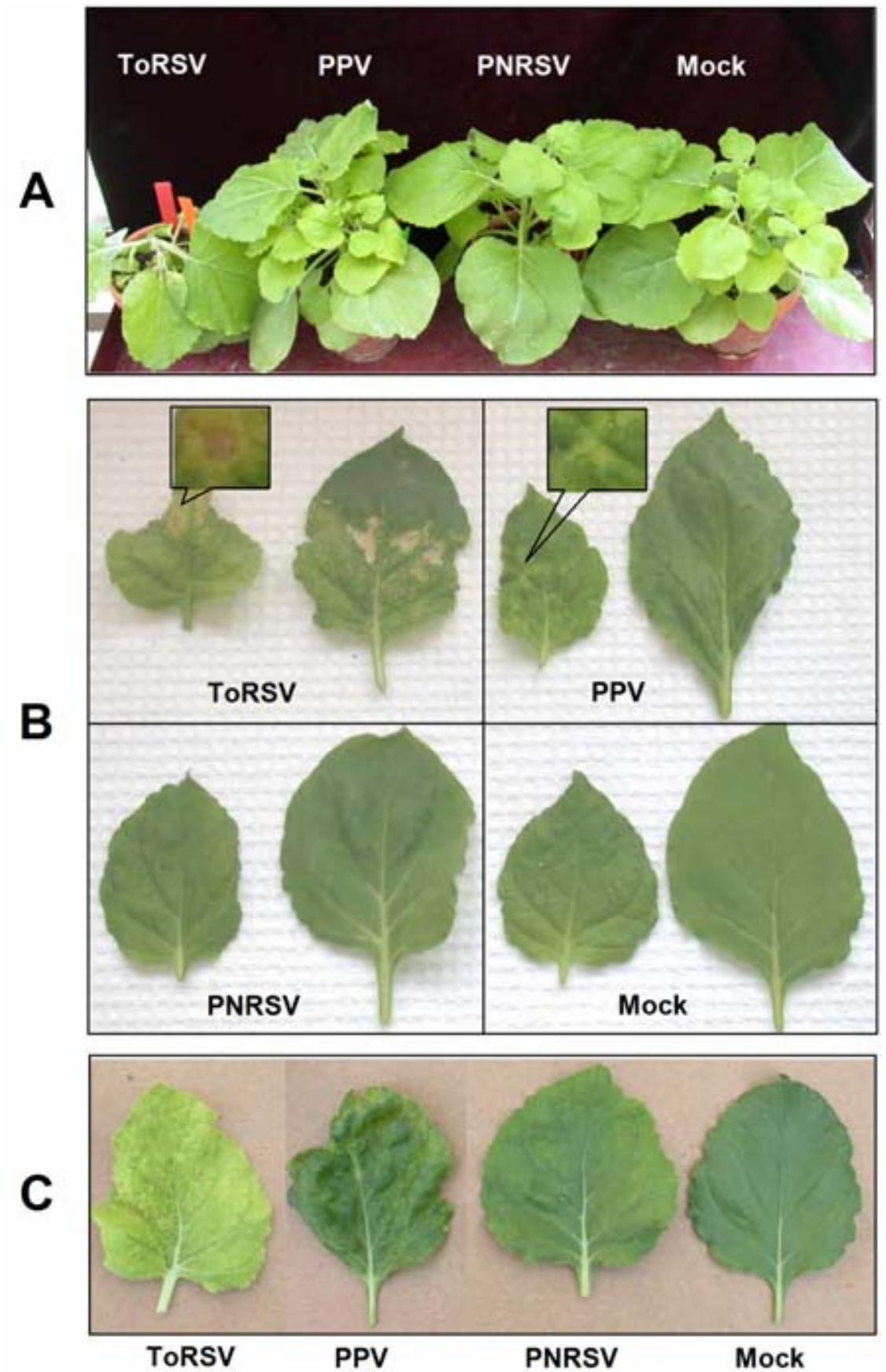

Fig. 2. Symptoms caused by Tomato ringspot nepovirus (ToRSV), Plum pox potyvirus (PPV), and Prunus necrotic ringspot ilarvirus (PNRSV) in Nicotiana benthamiana. Healthy mock-inoculated controls are indicated. A, Whole plants after 2 weeks postinoculation. B, Systemically infected leaves 2 weeks postinoculation. A representative young, newly emerging leaf is shown in the left of each panel while mature, fully expanded leaves are shown on the right. C, Systemic leaf symptoms 4 weeks postinoculation. 
to the activation of host defense responses (Atkinson and Mathews 1970; Xie et al. 2001). In this study, whole leaves from systemically infected plants were used. Thus, each RNA sample was derived from a mix of cell types, developmental stages, and disease states. As a consequence, genes that are profoundly altered only during specific developmental stages, in specific cell types, or in only certain zones of the leaf likely are diluted and appear as smaller changes. Likewise, genes that show opposite expression patterns among different tissues or disease states have the potential to cancel each other out. The data presented here represents an overall view of the leaf transcriptional response at a single time point during infection and the extent of up- or downregulation is not necessarily an indicator of the biological importance with respect to disease.
Cumulative changes in gene expression.

In all, 1,438 unique statistically significant genes were collectively identified for all three virus infections. The number of statistically significant genes identified from each virus treatment correlated with the severity of symptoms: 1,082 (ToRSV), 744 (PPV), and 89 (PNRSV). Relatively few genes were identified in PNRSV-infected plants, consistent with the overall mild symptoms induced by this virus. There was substantial overlap in the genes altered by each virus and, in most cases, the observed expression changes were in the same direction (i.e., induced in most or repressed in most) (Fig. 4). In all, $56 \%(417 / 744)$ of statistically significant genes identified from PPV-infected leaves also were altered in ToRSV-infected leaves, $87 \%$ (363/417) of which changed in the same direction.

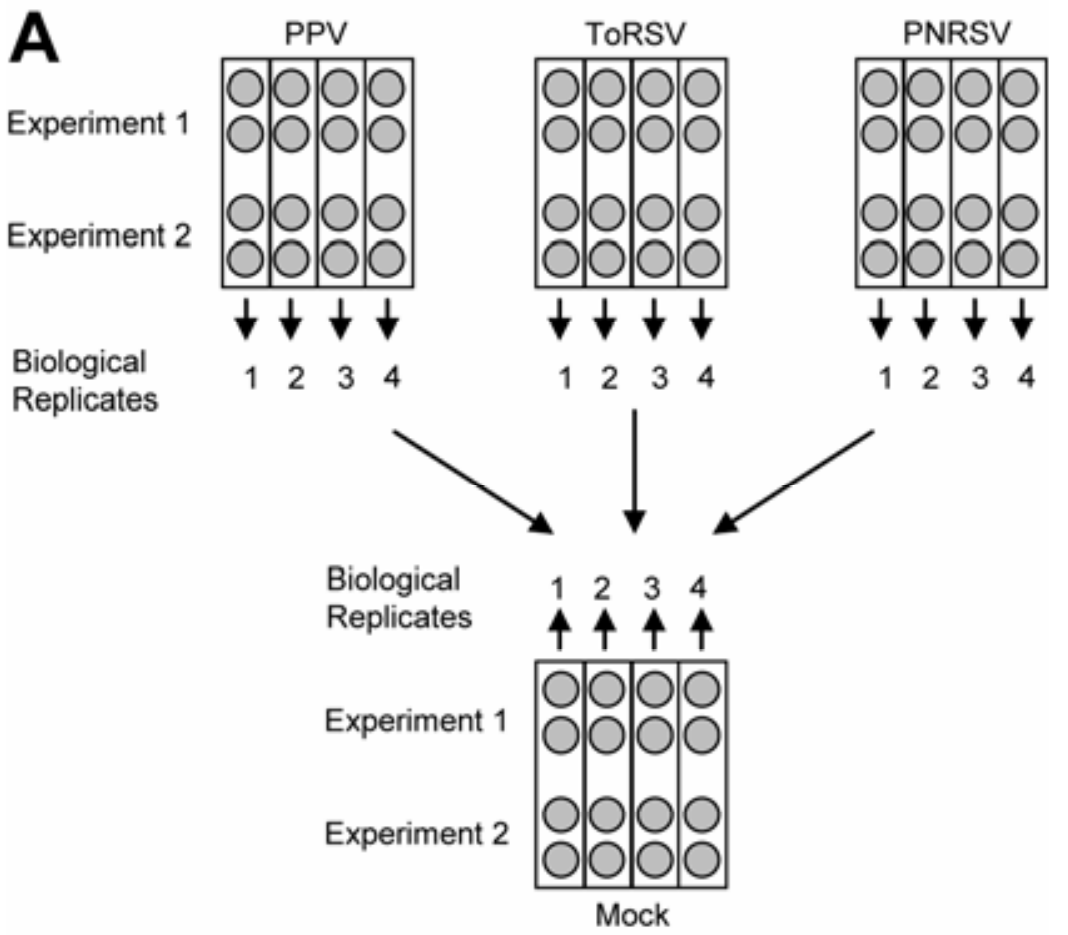

B

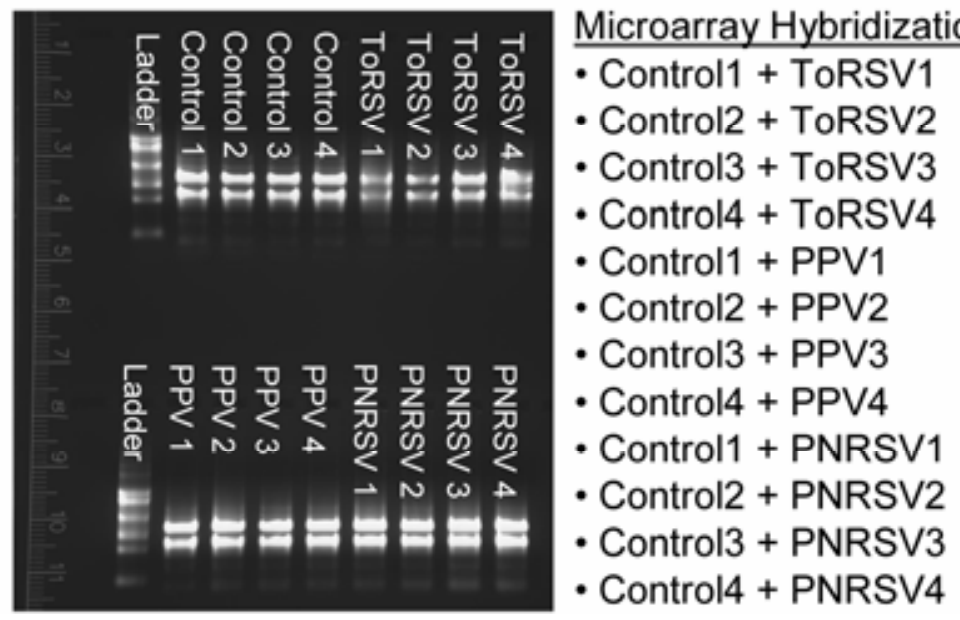

Fig. 3. Experimental design for microarray hybridizations. A, Two independent sets of 32 plants (labeled experiment 1 or 2) were inoculated with one of three viruses: Plum pox potyvirus (PPV), Tomato ringspot nepovirus (ToRSV), or Prunus necrotic ringspot ilarvirus (PNRSV) or mock inoculated. Each plant is represented by a gray circle. Biological replicates (numbered 1 to 4 ) for each virus infection and mock controls were obtained by pooling 16 to 20 leaves from four plants, two plants from each independently inoculated set. B, Ethidium-bromide-stained agarose gel of RNA samples (3 $\mu$ g per lane) used for cDNA labeling and subsequent microarray hybridization. Microarray hybridizations are listed and were done by hybridizing each virus infected biological replicate ( 1 to 4 ) to one of the four mock-inoculated control replicates for a total of 12 hybridizations. Dye swaps were performed for each of the 12 pairs of samples resulting in a total of 24 hybridizations. 
Seventy percent $(62 / 89)$ of the genes altered by PNRSV also were altered by PPV, ToRSV, or both. These data indicate that, despite differences in symptoms, there is significant overlap in the gene expression changes induced by these diverse viruses.

\section{Statistical analysis of functional categories.}

In this study, we focused on patterns of expression among different functional categories of genes to identify correlations with the observed symptoms, assuming that any individual gene is potentially a statistical anomaly whereas groups of functionally related genes with shared expression patterns would not occur by chance. Genes represented on the NSF potato array have both annotation and gene ontology (GO) information (Rensink et al. 2005). Upon initial data analysis, it became apparent that existing GO terms and annotation are, in many cases, incomplete or do not reflect published literature. Also, some GO categories are very general and offer little insight into biological mechanisms. Therefore, additional annotation and literature searches were conducted on the entire set of 1,438 statistically significant genes. This information was used to create a custom set of functional gene categories and subcategories (Table S2). The resulting classification scheme served as the context for all subsequent data analyses.

Four categories (unknown, protein synthesis/translation, chloroplast/light response/photosynthesis, and stress/pathogenesis) composed $51 \%$ of all statistically significant genes in this study (Fig. 5); however, because it was not possible to perform comparable annotations for all genes spotted on the microarray, it is not clear whether any of these categories represent enrichments in the virus treatments.

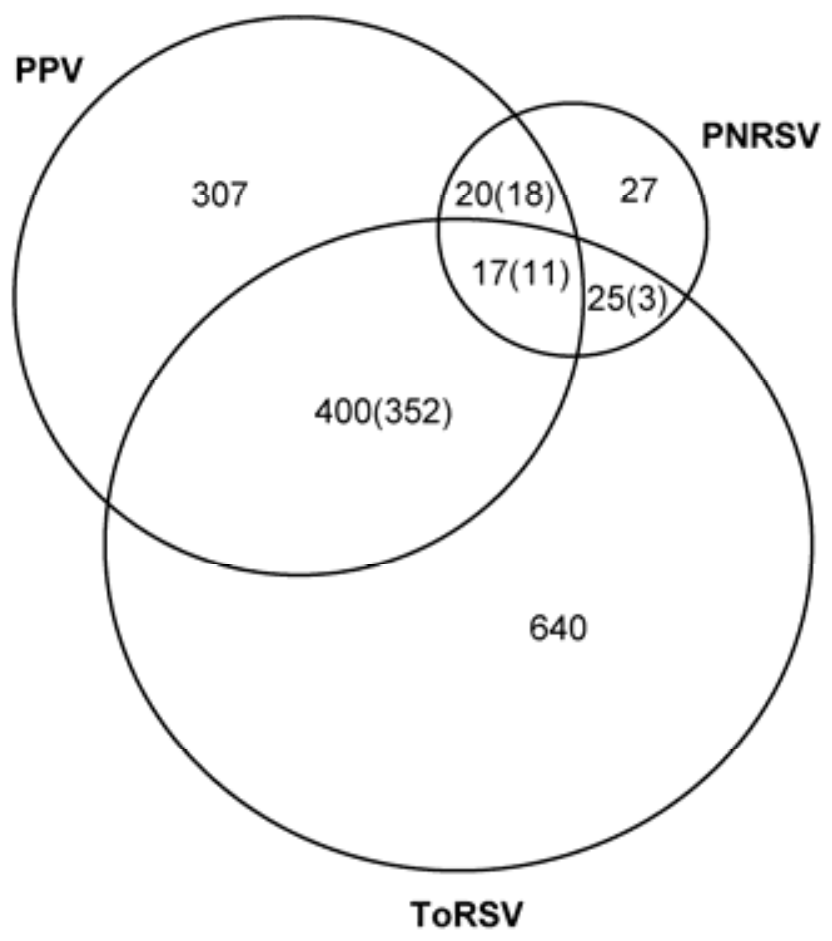

Fig. 4. Venn diagram showing overlap of gene expression between all three viruses: Plum pox potyvirus (PPV), Prunus necrotic ringspot ilarvirus, (PNRSV), and Tomato ringspot nepovirus (ToRSV). Values shown in the nonintersecting segments represent the number of statistically significant genes unique to each virus whereas values within intersections represent number of shared genes. Values in parentheses indicate the number of shared genes that changed in the same direction. For example, of the 17 statistically significant genes altered by all three viruses, 10 showed the same expression pattern (up in all or down in all).
After gene categorization, it became apparent that some categories and subcategories showed trends whereby most members within a category were either induced or repressed by one or more viruses. This prompted us to calculate the induced versus repressed gene ratio for each category and subcategory. First, the numbers of genes induced and repressed in each category and subcategory were tabulated for all three virus treatments (Fig. 6). Data from expanded secondary classifications were used for three categories (chloroplast function/photosynthesis, stress/pathogenesis, and virus interaction). To determine whether each ratio was statistically significant and exclude ratios that could have occurred by chance, $\chi^{2}$ and Fishers exact tests were performed on all categories and subcategories comprising at least 10 members. A similar approach was used by Kasuga and associates (2005) for enrichment analysis. The results for statistically significant categories $(P$ values $<0.05)$ are shown in Table 1 and the complete analysis is available in Table S3. No statistically significant categories were identified for PNRSV. The following are detailed descriptions of the results for each statistically significant category and subcategory.

\section{Plastid-associated genes.}

Several key metabolic functions take place within plastids, including amino acid biosynthesis, Calvin cycle, carbohydrate metabolism, and photosynthesis (Kleffmann et al. 2004). In both PPV- and ToRSV-infected leaves, widespread repression of genes associated with plastid function was observed. In all, 243 genes in this category were identified. ToRSV altered 198 of these genes, 91\% (181) of which were repressed. Among the 17 induced genes, 4 have known functions in chloroplast (STMIN38), chlorophyll (STMEJ57), or starch (STMGJ02) degradation and 1 inhibits chlorophyll biosynthesis (STMIL23). PPV altered the expression of 137 genes in this category, $83 \%$ (113) of which were repressed. Thirty-four percent $(83 / 243)$ of all plastid-related genes were repressed by both PPV and ToRSV. No overlap was identified among the induced genes. The observed repression extended to all plastid subcategories, including Calvin cycle, light harvesting, and photosynthesis. Statistically significant repression of amino acid biosynthesis and plastid ribosome genes was observed only for ToRSV.

Despite the extensive alterations of plastid-associated genes caused by both PPV and ToRSV, few plastid-encoded genes were identified as statistically significant. The Arabidopsis plastid genome contains 87 genes (Sato et al. 1999). Based on similarity to Arabidopsis counterparts, we estimated that approximately $30 \%$ (26) of all plastid-encoded genes are represented on the potato array (BLASTN e value $<\mathrm{e}^{-10}$, data not shown). Of these, only five genes were altered by one or more viruses (Table S4). Consequently, the repression of plastidrelated genes by both PPV and ToRSV was predominantly directed against nuclear-encoded genes.

\section{Protein synthesis and translation.}

In all, 194 genes with functions related to protein synthesis were identified as statistically significant. This category includes proteins associated with translation initiation and release factors, tRNA metabolism, Sec protein transport and folding, and ribosome proteins. In this category, 131 genes were altered by PPV infection, 80\% (105) of which were induced. In stark contrast, $75 \%(72 / 96)$ of the genes in this category were repressed by ToRSV.

The observed induction by PPV was due mostly to cytosolic ribosomal subunits, of which $99 \%$ (72/73) were induced (Fig. 7). In Arabidopsis, cytosolic ribosomes comprise over 70 subunits encoded by 227 genes (Barakat et al. 2001; Chang et al. 2005; Nakao et al. 2004). Through comparisons with Arabi- 
dopsis, it was determined that the genes induced by PPV represent $41 \%$ of all ribosomal genes printed on the array and encode $56 \%$ of all cytosolic large and small subunits (Table S5). In contrast to PPV, 80\% (35/44) of ribosomal genes altered by ToRSV were repressed. Much of the observed repression was due to plastidic ribosomal subunits, $87 \%(20 / 23)$ of which were repressed.

\section{Stress- or pathogenesis-associated genes.}

In all, 153 genes classified as stress- or pathogenesis-associated were identified as statistically significant in leaves infected by PPV (69), ToRSV (122), and PNRSV (6). These included many common stress or pathogenesis genes, including WRKY transcription factors, pathogenesis-related proteins, putative disease resistance genes, heat shock factors, and wound and senescence response genes. Widespread induction of these genes was observed for ToRSV (79\%; 96/122). PPV induced $70 \%$ $(48 / 69)$ of the genes in this category although this was not statistically significant. There was substantial overlap between PPV and ToRSV and, of the 39 genes shared by PPV and ToRSV, only 5 showed opposite expression patterns: 2 bZIP transcription factors were repressed by ToRSV but induced by PPV whereas 3 stress-associated genes were repressed by PPV and induced by ToRSV.

A set of 31 genes that commonly are induced by plant virus infection have been identified previously, most of which are related to pathogenesis and stress (Whitham et al. 2006). Of these 31 genes, $77 \%$ (24/31) were represented by similar sequences in the 1,438 statistically significant genes we identified and $79 \%(19 / 24)$ had at least 1 similar gene that was likewise induced by one or more viruses (Table S6). Of the genes that were induced by both PPV and ToRSV, 62\% (13/21) were stress or pathogenesis associated. The five exceptions not in- duced in this study fell into the following categories (Whitham et al. 2006): cell-wall-related, lipase, kinase, oxidation or reduction, and diterpenoid biosynthesis. None were found to be induced by PNRSV.

Genes in the pathogenesis or stress category were further categorized as biotic or abiotic stress-associated genes. ToRSV induced $76 \%(39 / 51)$ of abiotic and $61 \%$ (37/61) of biotic stress genes. A subcategory of abiotic stress composed of waterdeficit response genes showed statistically significant induction $(92 \%, 12 / 13)$ by ToRSV.

\section{Metal/metal binding.}

Genes in this category primarily included metallothioneins, metal-binding proteins, and copper-related genes. Although specific functions are not known for most of these genes, as a category they showed a general pattern of induction by both PPV and ToRSV, though only ToRSV was statistically significant. In all, 83 and $87 \%$ (10/12 and 13/15), respectively, were induced. Eleven genes were altered by both PPV and ToRSV and all changed in the same direction. Two of these genes were similar to a known metallothionein from tobacco previously shown to be both TMV and wound inducible (Choi et al. 1996).

\section{Categories uniquely induced by ToRSV.}

Three categories of genes uniquely showed statistically significant induction by ToRSV. In all, 69\% (22/32) of energy/ mitochondria genes, 68\% (32/47) of membrane/cytoskeleton/ intracellular transport genes, and 72\% (33/46) of proteolysis/ proteasome genes were induced by ToRSV. Thirty-six percent (17/47) of the induced genes in the membrane/cytoskeleton/ intracellular transport category fell into the subcategory of vesicle trafficking, which by itself also was statistically significant.

\section{Distribution of genes within categories}

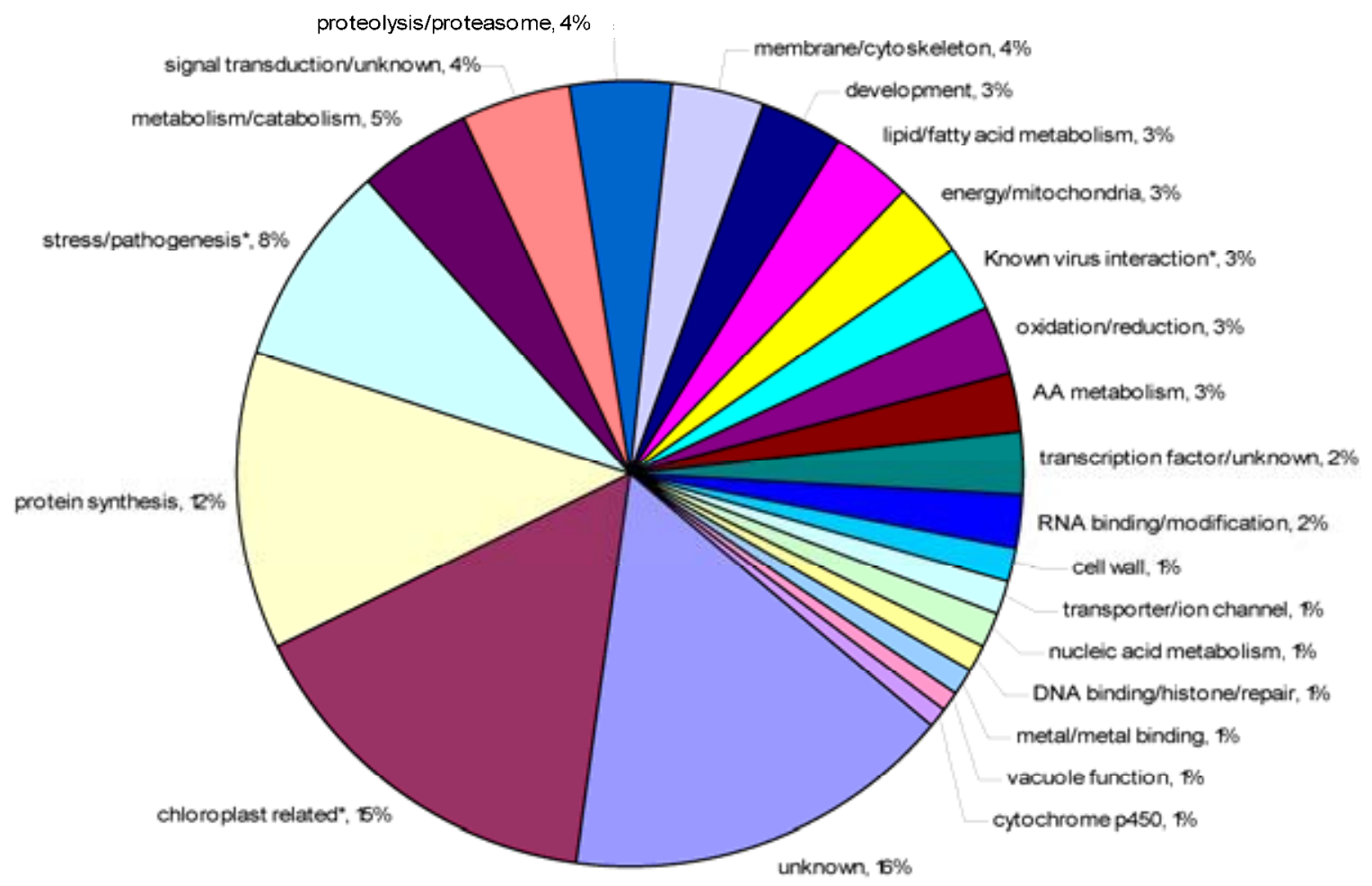

Fig. 5. Distribution of statistically significant genes by category. Pie chart showing the relative contribution of each functional category to the collective sum of statistically significant genes for all three viruses. Category is indicated next to each pie slice. In some cases, category names have been abbreviated due to space limitations. 


\section{Confirmation of microarray data}

by real-time polymerase chain reaction.

The general validity of the microarray data was verified by real-time polymerase chain reaction (PCR) using a small subset of statistically significant genes. To achieve more robust validation, virus inoculations were repeated and new RNAs (not used for microarray experiments) were obtained. PCR primers were designed for 38 genes chosen to represent a wide range of different functional categories. When available, primer sequences were designed against $N$. benthamiana homologs of the potato genes. Of these 38, 11 both amplified single cDNA fragments of the expected size and showed linear amplification in real-time PCR experiments. Gene IDs and primer sequences for all 11 are shown in Table 2 . The resulting ex-

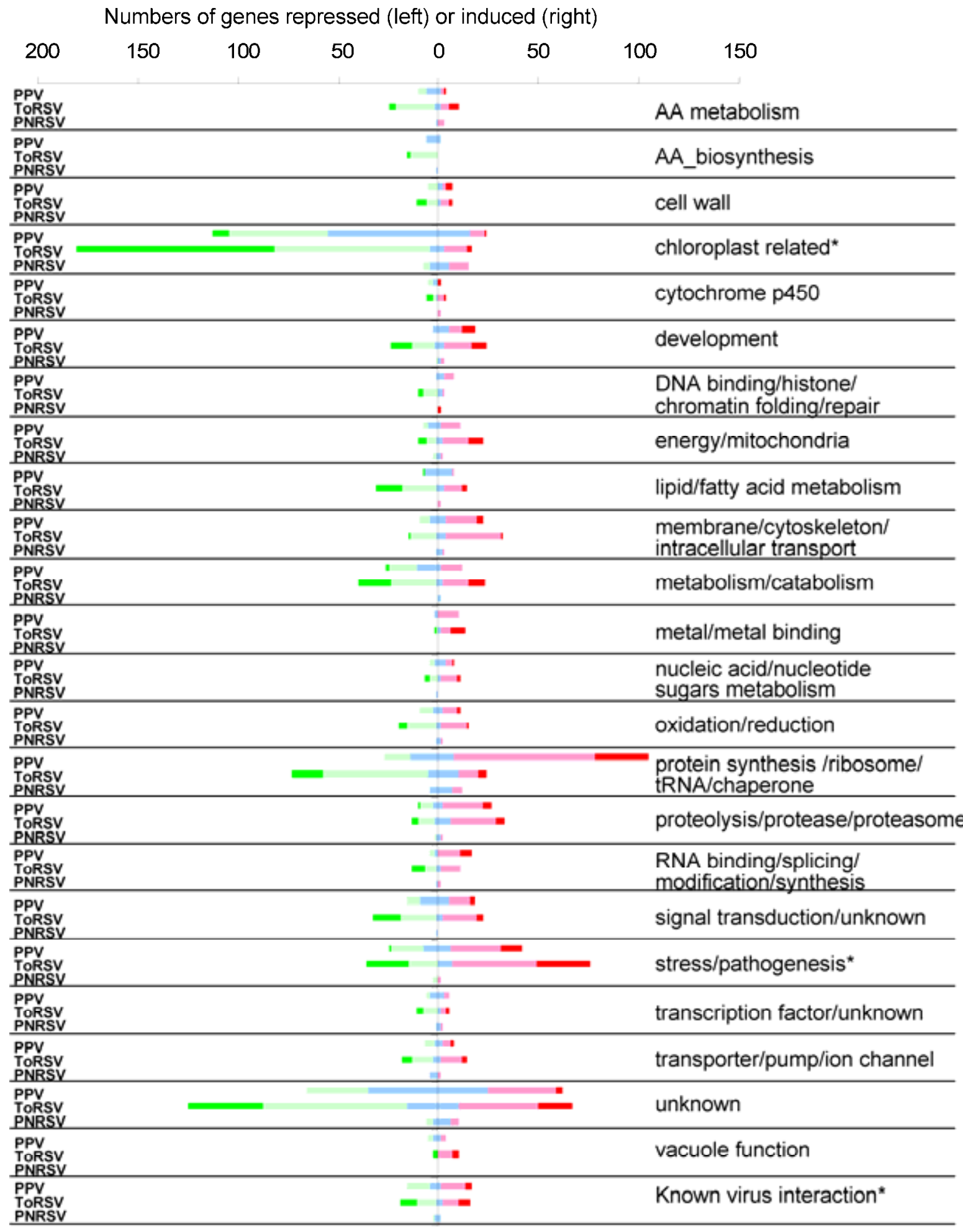

Fig. 6. Impacts of each virus on each functional category. PPV $=$ Plum pox potyvirus, ToRSV = Tomato ringspot nepovirus, and PNRSV $=$ Prunus necrotic ringspot ilarvirus. X-axis scale at top represents numbers of genes. Bars represent the number of genes induced or repressed by each virus within each category. Categories tabulated from expanded secondary classifications are indicated with an asterisk (*). Numbers of induced or repressed genes are shown to the right and left of the central Y axis, respectively. Scale indicates fold change: Black $>1.5$-fold, dark gray $>1.15$-fold, and light gray $>$ or $<1$. 
pression data is shown in Table 3. All 11 confirmed expected results from microarray data with the exception of STMDH96, which was identified as repressed by ToRSV in microarray experiments but showed induction in real-time PCR experiments.

\section{DISCUSSION}

Over the past century, the impact of viruses on host morphogenic, cellular, structural, physiological, and biochemical properties has been documented extensively. Collectively, these studies show that viruses can alter host function at almost every level. Leaf, root, stem, fruit, and flower morphology can change, cellular organelles often become damaged, novel viral-induced cellular structures and inclusions appear, and photosynthetic capacity and other metabolic processes are altered (Mathews 1991). The ability of viruses to interfere with these basic host functions offers opportunities to not only decipher the molecular events associated with symptom development but also provide a means to probe basic plant functions (Biemelt and Sonnewald 2006). By comparing the global gene expression profiles of systemically infected $N$. benthamiana leaves challenged with three different fruit tree viruses that cause distinct symptoms, it was possible to draw some general correlations between patterns of gene expression and symptoms. Although these correlations are strictly circumstantial and not necessarily causative, overall they reveal some likely associations. Moreover, many of the observed expression changes are supported in the literature, including a number of functional examples.
The number of genes altered by each virus was consistent with the severity of the observed symptoms. Gene expression data largely reflected these differences because ToRSV, which induced the most damaging symptoms, altered the most genes (1,041), followed by PPV (679) and PNRSV (75). A similar result was obtained previously by comparing the expression profiles of two distinct enveloped viruses, Sonchus yellow net virus (SYNV) and Impatiens necrotic spot virus (INSV), in $N$. benthamiana. INSV caused more severe symptoms than SYNV and, likewise, substantially more gene expression changes at comparable time points. Sixty-two percent of the genes altered by SYNV also were altered by INSV, similar to the $56 \%$ overlap observed between PPV and ToRSV (Senthil et al. 2005). The observed overlap implies a great deal of similarity in the host response to each virus; however, when analyzed in depth, the similarities appear to be restricted to particular categories of genes. Because the microarray experiments presented here were rather limited (i.e., performed at a single time point using mixtures of systemically infected leaves of different ages and degrees of infection), the observed correlation between numbers of expression changes and symptom severity likely is due to the overall health of the infected plants. Many profound expression changes that take place only in specific tissue types or diseased states likely were diluted and were not observed.

\section{Repression of plastid-associated genes.}

Chlorosis is one of the most common symptoms caused by plant virus infection and often is associated with reduced pho-

Table 1. Functional categories displaying nonrandom expression trends $\mathrm{s}^{\mathrm{a}}$

\begin{tabular}{|c|c|c|c|c|c|c|c|c|c|}
\hline Category, subcategory & Total no. of genes & Virus $^{a}$ & No. per virus & E-up & O-up & E-down & O-down & $\chi^{2 \mathrm{~b}}$ & Fishers test $^{b}$ \\
\hline \multirow[t]{2}{*}{ AA metabolism } & 41 & PPV & 14 & 8 & 4 & 6 & 10 & $\ldots$ & $2.5 \mathrm{E}-01$ \\
\hline & & ToRSV & 34 & 14 & 10 & 20 & 25 & $\ldots$ & $3.2 \mathrm{E}-01$ \\
\hline \multirow[t]{2}{*}{ AA_biosynthesis } & 19 & PPV & 7 & 4 & 1 & 3 & 6 & NA & NA \\
\hline & & ToRSV & 16 & 7 & 0 & 9 & 16 & & $6.8 \mathrm{E}-03$ \\
\hline \multirow[t]{2}{*}{ Chloroplast related $^{\mathrm{c}}$} & 243 & PPV & 137 & 76 & 24 & 61 & 113 & 2.7E-11 & $\ldots$ \\
\hline & & ToRSV & 197 & 80 & 17 & 117 & 180 & 4.4E-09 & $\ldots$ \\
\hline \multirow[t]{2}{*}{ Calvin cycle } & 26 & PPV & 14 & 8 & 1 & 6 & 13 & $\ldots$ & 1.3E-02 \\
\hline & & ToRSV & 24 & 10 & 0 & 14 & 24 & $\ldots$ & $6.0 \mathrm{E}-04$ \\
\hline \multirow[t]{2}{*}{ Light harvesting } & 37 & PPV & 19 & 11 & 4 & 8 & 15 & $\ldots$ & 4.5E-02 \\
\hline & & ToRSV & 32 & 13 & 2 & 19 & 30 & $\ldots$ & $2.4 \mathrm{E}-03$ \\
\hline \multirow[t]{2}{*}{ Photosynthesis } & 44 & PPV & 23 & 13 & 3 & 10 & 20 & $\ldots$ & 4.5E-03 \\
\hline & & ToRSV & 36 & 15 & 1 & 21 & 35 & $\ldots$ & 1.0E-04 \\
\hline \multirow[t]{2}{*}{ Energy/mitochondria } & 48 & PPV & 19 & 11 & 11 & 8 & 8 & $\ldots$ & $1.0 \mathrm{E}+00$ \\
\hline & & ToRSV & 32 & 13 & 22 & 19 & 10 & $\ldots$ & 4.4E-02 \\
\hline \multirow[t]{2}{*}{ MCI transport ${ }^{\mathrm{d}}$} & 61 & PPV & 31 & 17 & 22 & 14 & 9 & $\ldots$ & $2.9 \mathrm{E}-01$ \\
\hline & & ToRSV & 47 & 19 & 32 & 28 & 15 & $\ldots$ & 1.3E-02 \\
\hline \multirow[t]{2}{*}{ Vesicle trafficking } & 23 & PPV & 13 & 7 & 11 & 6 & 2 & $\ldots$ & $2.0 \mathrm{E}-01$ \\
\hline & & ToRSV & 17 & 7 & 14 & 10 & 3 & $\ldots$ & $3.2 \mathrm{E}-02$ \\
\hline \multirow[t]{2}{*}{ Metal_metal binding } & 16 & PPV & 12 & 7 & 10 & 5 & 2 & $\ldots$ & 3.7E-01 \\
\hline & & ToRSV & 15 & 6 & 13 & 9 & 2 & $\ldots$ & 2.1E-02 \\
\hline \multirow[t]{2}{*}{ Protein synthesis } & 194 & PPV & 131 & 73 & 105 & 58 & 27 & 4.2E-05 & $\ldots$ \\
\hline & & ToRSV & 96 & 39 & 24 & 57 & 73 & 3.2E-02 & $\ldots$ \\
\hline \multirow[t]{2}{*}{ Ribosome_chloroplast } & 29 & PPV & 13 & 7 & 5 & 6 & 8 & $\ldots$ & 7.0E-01 \\
\hline & & ToRSV & 24 & 10 & 3 & 14 & 21 & $\ldots$ & 4.9E-02 \\
\hline \multirow[t]{2}{*}{ Ribosome_cytosolic } & 89 & PPV & 73 & 40 & 72 & 32 & 1 & $\ldots$ & 4.6E-11 \\
\hline & & ToRSV & 20 & 8 & 5 & 12 & 15 & $\ldots$ & $5.0 \mathrm{E}-01$ \\
\hline \multirow[t]{2}{*}{ Proteolysis_proteasome } & 66 & PPV & 36 & 20 & 26 & 16 & 10 & $\ldots$ & $2.2 \mathrm{E}-01$ \\
\hline & & ToRSV & 46 & 19 & 33 & 27 & 13 & $\ldots$ & 5.9E-03 \\
\hline \multirow[t]{2}{*}{ Stress_pathogenesis ${ }^{\mathrm{c}}$} & 130 & PPV & 67 & 37 & 42 & 30 & 25 & 3.8E-01 & $\ldots$ \\
\hline & & ToRSV & 112 & 46 & 76 & 66 & 36 & 2.0E-04 & $\ldots$ \\
\hline \multirow[t]{2}{*}{ Abiotic_stress } & 54 & PPV & 17 & 9 & 12 & 8 & 5 & $\ldots$ & 4.8E-01 \\
\hline & & ToRSV & 51 & 21 & 39 & 30 & 12 & 9.3E-04 & $\ldots$ \\
\hline \multirow[t]{2}{*}{ Water_deficit } & 14 & PPV & 5 & 3 & 2 & 2 & 3 & NA & NA \\
\hline & & ToRSV & 13 & 5 & 12 & 8 & 1 & $\ldots$ & 1.1E-02 \\
\hline \multirow[t]{2}{*}{ Biotic_stress } & 76 & PPV & 50 & 28 & 30 & 22 & 20 & $6.3 \mathrm{E}-01$ & $\ldots$ \\
\hline & & ToRSV & 61 & 25 & 37 & 36 & 24 & 4.4E-02 & $\ldots$ \\
\hline
\end{tabular}

${ }^{a} \mathrm{PPV}=$ Plum pox potyvirus and ToRSV $=$ Tomato ringspot nepovirus .

${ }^{\mathrm{b}}$ Statistically significant values $(P<0.05)$ are shown in bold. NA $=$ not available.

${ }^{c}$ Numbers of genes were derived from secondary categories that span multiple primary categories.

${ }^{\mathrm{d}} \mathrm{MCI}=$ membrane_cytoskeleton_intracellular. 


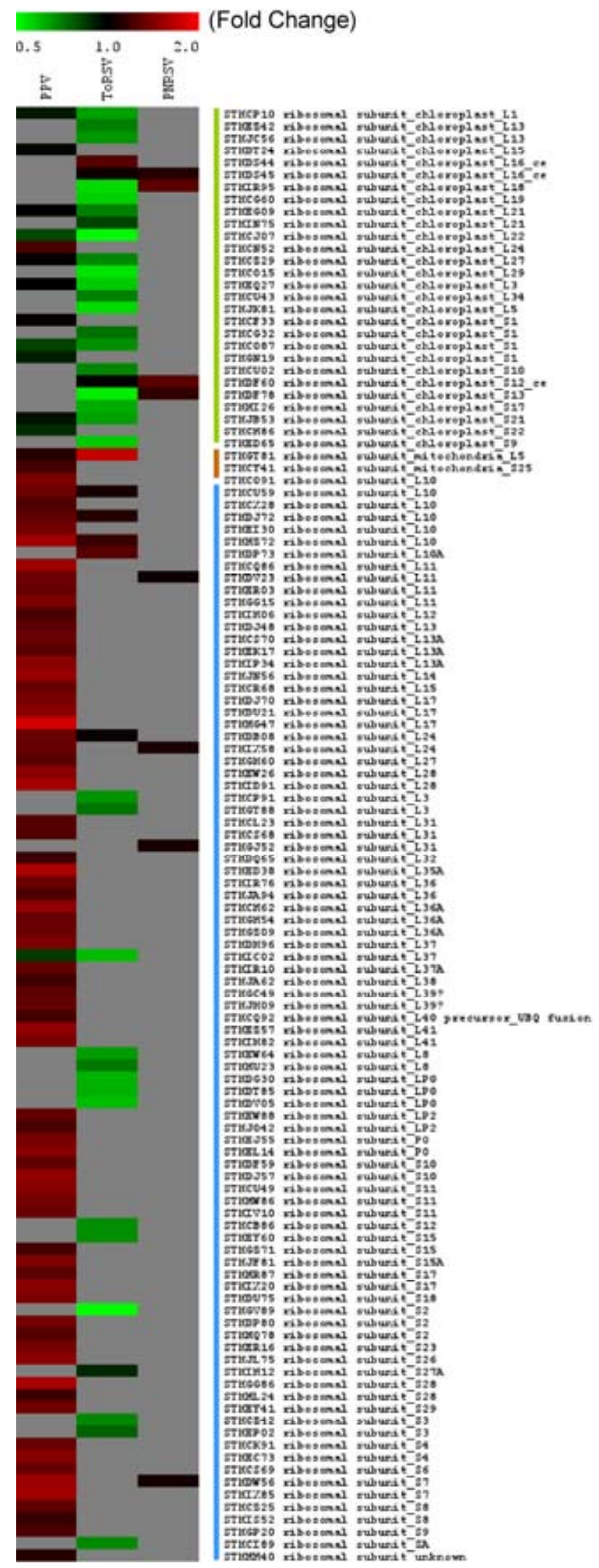

Fig. 7. Induction of genes encoding nuclear ribosomal proteins by Plum pox potyvirus (PPV). Heat map representation for all genes encoding ribosomal protein subunits altered by PPV, Tomato ringspot nepovirus (ToRSV), or Prunus necrotic ringspot ilarvirus (PNRSV) is shown. Scale is shown at top. Gene annotations including subunit designations are shown to the right. Chloroplast, mitochondrial, and cytoplasmic ribosomal subunits are indicated. tosynthetic capacity (Mathews 1991). Mosaic patterns typically are observed; however, general yellowing, rings, or spots are also common. All three viruses used in this study caused observable chlorosis but manifested in different ways. ToRSV infection triggered pronounced yellowing in systemically infected leaf tissue that became more widespread as leaves matured. PPV infection produced mosaic symptoms typical for potyviruses. At the time of leaf collection, few or no symptoms were observed for PNRSV-infected plants, although mild mottling could be observed in infected leaves after several weeks. Consistent with these symptoms, repression of plastid-associated genes was observed for both PPV and ToRSV but not PNRSV and the overall level of repression was associated with the severity of chlorotic symptoms-although it is not known where and in which cell types repression takes place. ToRSV repressed two additional categories of genes also associated with plastids (amino acid biosynthesis and plastidic ribosomal subunits) that did not show statistically significant repression by PPV.

It is not known whether repression by each virus is achieved through the same or different mechanisms. One possible mechanism could be the degradation and destruction of plastids themselves. Although little is known about the cytopathic effects of ToRSV infection, PPV is known to have damaging effects on chloroplasts and commonly causes chloroplast membranes to rupture (Minoiu 2002). In ToRSV-infected leaves, several genes with known functions in chloroplast, chlorophyll, or starch degradation were induced, indicating that there may be concerted reprogramming events that lead to repression of plastid-associated genes and their subsequent degradation. Although chloroplast degradation cannot be ruled out as the cause of repression, the lack of impact on chloroplast-encoded genes suggests that chloroplasts and chloroplast gene regulation in general remain intact.

Communication between plastids and the nucleus has been documented extensively. At least five different pathways are known that control the expression of thousands of plastid-associated genes encoded within the nucleus (Beck 2005). Consequently, ample opportunity exists for viruses to interfere with these avenues of communication in a variety of ways. Repression of some plastid-associated genes by viruses has been hypothesized to occur as a consequence of impaired carbon partitioning and increased carbohydrate accumulation in source tissues that leads to subsequent repression of photosynthetic machinery (Herbers et al. 1997). This has been attributed to the action of viral movement proteins. Transgenic plants expressing high levels of a luteovirus movement protein showed both symptom development and carbohydrate accumulation in source tissues (Herbers et al. 1997). Carbohydrate accumulation was accompanied by reduced levels of Rubisco protein. By comparing different transgenic lines, the authors theorized that alterations in plasmodesmal gating impair carbohydrate phloem loading, thus causing accumulation in source tissues. Seemingly in contrast, plants expressing TMV movement protein also showed changes in carbon allocation; however, this function could be uncoupled from plasmodesmal gating (Balachandran et al. 1995). In this example, the authors concluded that the TMV movement protein may interact with other host factors to alter carbon allocation. It is not clear whether the widespread repression of plastid-associated genes in our study could have resulted from changes in carbon allocation because a mixture of source and sink tissues likely were collected. In the case of ToRSV, stem necrosis and subsequent phloem blockage or the action of the ToRSV-encoded movement protein could inhibit carbon partitioning and subsequent repression of photosynthesis-related genes. Despite this possibility, it seems unlikely that this mechanism alone can also explain the repression of nonphotosynthetic plastid functions 
such as amino acid and protein synthesis. PPV and other potyviruses do not encode a single movement protein, and this function has been attributed to several different proteins, including helper component protein (HCPro), coat protein (CP), and cylindrical inclusion protein $(\mathrm{CI})$ that also controls virus replication (Carrington et al. 1998; Rojas et al. 1997). Interestingly, PPV CI recently was shown to interact with the photosystem I subunit PsaK and repression of PsaK led to higher PPV accumulation in inoculated leaves (Jimenez et al. 2006). Here, ToRSV repressed PsaK expression but PPV did not, consistent with previous results of Jimenez and associates (2006). For some potyviruses, virus replication occurs in vesicles formed from the outer chloroplast membrane bilayer and viral $\mathrm{CP}$ has been identified within chloroplasts, negatively effecting photosynthesis and photosystem II activity (Fu et al. 2004). Although this has not been established for PPV, it was found to promote the formation of inclusion bodies situated in close proximity to rupturing chloroplast membranes and could cause similar effects (C. Dardick and C. Murphy, unpublished). Taken together, these data indicate that multiple synchronous mechanisms distinct for each virus likely contribute to the widespread repression of plastid-associated genes.

At the time of submission of this manuscript, Shimizu and associates (2007) similarly reported the repression of plastidassociated genes in rice by a double-stranded RNA virus (Rice $d$ warf virus) which causes chlorotic specks and stunting. This suggests that repression of plastid-associated genes may be a feature common to many plant viruses. Why do these diverse viruses target plastid function? It seems somewhat counterintui- tive because plastids perform essential functions that also should be important for virus replication such as amino acid biosynthesis. Even if impairment of plastid function occurs in a manner that is not limiting to virus replication, why does it occur at all? It could largely be a consequence of some general feature of virus pathogenesis, such as plasmodesmal gating by virus cellto-cell movement proteins that alter phloem-loading capacity and partitioning of carbohydrates and other metabolites (Herbers et al. 1997). An alternative possibility proposed by Abbink and associates (2002) is that, by disabling chloroplasts, viruses circumvent or inhibit the activation or action of plant-defense responses. At least two studies have shown that repression of specific photosystem subunits permits increased accumulation of unrelated viruses (Abbink et al. 2002; Jinenez et al. 2006). Moreover, the key defense signaling hormones salicylic acid (SA) and jasmonic acid (JA) are formed from amino acid biosynthesis intermediates located predominantly if not entirely in chloroplasts (Mauch et al. 2001; Schmid and Amrhein 1995; Wasternack et al. 2006). Together, these findings suggest that disabling plastid function may impair host defense signaling and, in some cases, could be a prerequisite for productive virus infection; possibly explaining why diverse viruses target plastid function.

\section{Impacts on host translational machinery.}

Because plant viruses do not encode their own protein synthesis machinery, they must co-opt the host cell machinery to translate viral RNAs and produce viral proteins. Thus, viral RNAs must directly compete with host mRNAs for these re-

Table 2. Real-time polymerase chain reaction primers and gene targets

\begin{tabular}{|c|c|c|c|c|}
\hline $\begin{array}{l}\text { Potato } \\
\text { array gene } \\
\text { ID }\end{array}$ & $\begin{array}{c}\text { GenBank } \\
\text { ID }^{\mathbf{a}}\end{array}$ & Subclass & Forward primer $\left(5^{\prime}-3^{\prime}\right)$ & Reverse primer $\left(5^{\prime}-3^{\prime}\right)$ \\
\hline STMEF75 & BQ118920 & chloroplast_chlorophyll_biosynthesis & AGTGGAGTCTGGAGCTCATTGCAT & CACAAGAGGTGTTTGTGGGCACTT \\
\hline STMIB20 & Q9XIY9* & pathogenesis_PR gene & TTATGTGAGGCTCAAAGCCGGT & TGTGCCACGAACCCATTTCTCA \\
\hline STMHL75 & Q852T0* & vacuole_protein processing & TGCCACAACAGCATCAAACGCT & TGACCAGGTGATATTGCTGCCT \\
\hline STMCR18 & Q8VWQ1* & stress_dehydration & TCCCATGCCCAAGGCAATCAAA & ACCCTTGCCGGTGTTGACATTT \\
\hline STMID91 & BQ513312 & protein synth_ribosome_L28 & AGAATGGCCAAGGCTGTAACCA & TTGCAAGTCACACGCCATAGCA \\
\hline STMDH96 & T46225* & protein synth & TGCAAACACAGGCAGCTCATCA & TTGACTGCCTTGCTCCTGGAAA \\
\hline STMEF49 & Q9M6E0* & pathogenesis_WRKY4 & TGGTGGATGATGGTCATGCTTGGA & TTCTGCACCTGCTTGGTTGCTT \\
\hline STMGP48 & Q94IQ1* & oxidation & TGAAACCCTAGCCAACCTTCCA & TGGCCACCAGAAAGTGCAACAA \\
\hline STMHT08 & BQ511673 & amino acid_catabolism_branch-chain & TTTCCTGGAGGACAGCTTCCAA & GCCAATTCTTTGCTCACCTCCT \\
\hline STMCF47 & BQ112154 & carbon fixation & ATGTACCTGTGGCAGTGGAAGAGA & ATCATCTCCATGATCAGCGAGGCA \\
\hline STMEY49 & Q40565* & chloroplast_photosynthesis & TGCCAACAAAGCACCGTTGAGT & TCGGTCTGTTTCTTGGGATCGACA \\
\hline
\end{tabular}

a Primer sequences were derived from Nicotiana benthamiana for genes having GenBank homologs; otherwise, potato sequences were used.

Table 3. Validation of microarray data using real-time polymerase chain reaction

\begin{tabular}{|c|c|c|c|c|c|c|}
\hline Gene ID & Subcategory & $\begin{array}{l}\text { Real-time result } \\
\text { (fold change) }\end{array}$ & $\begin{array}{l}\text { Microarray mean } \\
\text { (fold change) }\end{array}$ & Microarray range & Expected & Validated \\
\hline \multirow[t]{2}{*}{ STMEF75 } & chloroplast_chlorophyll biosynthesis & 0.86 & 0.60 & $0.48-1$ & ToRSV_down & Yes \\
\hline & & 2.36 & 1.31 & $0.98-1.72$ & PNRSV_up & Yes \\
\hline \multirow[t]{2}{*}{ STMIB20 } & pathogenesis_PR gene & 36.15 & 1.60 & $1.7-2.6$ & PPV_up & Yes \\
\hline & & 341.37 & 1.53 & $0.96-2.48$ & ToRSV_up & Yes \\
\hline STMHL75 & vacuole_protein processing & 1.79 & 2.95 & $1.21-9.84$ & ToRSV_up & Yes \\
\hline STMCR18 & stress_dehydration & 2.26 & 1.62 & $1.57-3.33$ & ToRSV_up & Yes \\
\hline STMID91 & protein synthesis ribosome_L28 & 1.94 & 1.64 & $1.2-1.66$ & PPV_up & Yes \\
\hline \multirow[t]{2}{*}{ STMDH96 } & protein synthesis_NAC & 3.78 & 0.62 & $0.56-0.72$ & ToRS̄V_down & No \\
\hline & & 5.96 & 1.41 & $1.22-1.93$ & PNRSV_up & Yes \\
\hline \multirow[t]{2}{*}{ STMEF49 } & pathogenesis_WRKY4 & 6.61 & 1.75 & $1.41-3.12$ & PPV_up & Yes \\
\hline & & 49.90 & 1.37 & $1.09-2.02$ & ToRSV_up & Yes \\
\hline STMGP48 & oxidation_peroxidase & 2.84 & 2.11 & $1.77-6.88$ & ToRSV_up & Yes \\
\hline \multirow[t]{2}{*}{ STMHT08 } & amino acid_catabolism & 0.79 & 0.77 & $0.39-1.05$ & PPV_down & Yes \\
\hline & & 1.23 & 1.59 & $0.83-2.77$ & ToRSV_up & Yes \\
\hline \multirow[t]{2}{*}{ STMCF47 } & Carbon fixation & 0.50 & 0.64 & $0.25-0.94$ & PPV_down & Yes \\
\hline & & 0.08 & 0.53 & $0.29-0.85$ & ToRS̄V_down & Yes \\
\hline \multirow[t]{2}{*}{ STMEY49 } & chloroplast_photosynthesis & 0.75 & 0.78 & $0.28-0.94$ & PPV_down & Yes \\
\hline & & 0.53 & 0.46 & $0.2-0.97$ & ToRSV_down & Yes \\
\hline
\end{tabular}


sources. PPV uniquely showed widespread induction of protein synthesis-related genes. The observed induction was due primarily to the increased expression of large numbers of cytosolic ribosome subunits. This is consistent with previous EM studies indicating that PPV-infected peach leaves contain increased nucleoprotein synthesis and numbers of ribosomes (Brunt et al. 1997; Rankovic 1974). Further studies are needed to determine whether or not increased ribosome gene expression is required for productive PPV infection and which PPV protein or proteins are responsible. In budding yeast, much of the ribosome machinery is controlled by two regulons: the ribosome protein (RP) regulon that controls ribosome genes and the rRNA and ribosome biosynthesis (RRP) regulon that includes over 200 ribosome biosynthesis and rRNA genes (Wade et al. 2006). Plant ribosomal protein genes likewise may be controlled by one or a few such regulons. Understanding how PPV promotes induction of these genes would provide insight into this basic plant function and possibly enable strategies to increase protein expression beyond that normally obtainable in transgenic plants.

PPV and ToRSV, despite having distinct particle morphology, have similar replication strategies, including poly-A tails, 5' viral-encoded VPg cap proteins, and the production of proteolytically cleaved polyproteins. Despite these common features, it appears they create dramatically different cellular environments for replication and translation of viral proteins. It may be that two opposing strategies are employed by these viruses to compete with host mRNAs for protein synthesis machinery. In the case of PPV, upregulation of translation-associated genes may produce excess machinery and provide the additional resources needed for viral RNAs. In contrast, ToRSV may gain a competitive advantage by repressing specific host components needed for host mRNAs but dispensable for viral RNA processes. In support of this, ToRSV exclusively repressed genes with functions in RNA splicing (STMGF94 and STMCY75) and induced genes with functions in mRNA decapping (STMDB11 and STMGN04). Alternatively, these findings may represent contrasting host-mediated responses. In the case of PPV, the plant may respond to viral competition for translation machinery by inducing expression of translation genes, whereas the response to ToRSV infection could represent a form of defense whereby repression of specific components of the translation machinery inhibits virus replication while sustaining mRNA translation.

\section{Induction of biotic and abiotic stress genes.}

A common aspect of plant virus infection that has been illuminated by expression profiling experiments is the induction of biotic and abiotic stress response genes (Chen et al. 2002; Golem and Culver 2003; Huang et al. 2005; Marathe et al. 2004; Senthil et al. 2005; Trinks et al. 2005; Whitham et al. 2003, 2006). Consistent with these findings, both PPV and ToRSV induced the expression of large numbers of pathogenesis- or stress-related genes, many of which were induced by both viruses. A subset of these genes overlapped with a previously identified set of genes found to be commonly induced by virus infection in both Arabidopsis and N. benthamiana. PPV and ToRSV differed in the induction of abiotic stress genes, most of which were induced by ToRSV but not PPV. Induced genes included a statistically significant number of water-deficit response genes. The induction of these pathways by ToRSV could result from stem necrosis and blockage of vascular tissue, which likely cuts off water supplies to the aerial parts of the plant and causes the observed wilting of the upper leaves.

Surprisingly, PNRSV did not induce the expression of any pathogenesis- or stress-related genes, and all six genes identified in this category were repressed. Given the overall mild symp- toms caused by PNRSV infection, it appears that this virus is able to infect $N$. benthamiana in a manner that does not trigger systemic stress or defense responses. Many virus-host combinations are known to allow virus accumulation in the absence of discernable symptoms, sometimes called tolerant or latent infection. Plant gene expression responses to such tolerant infections are largely unexplored but likewise may be limited.

\section{Induction of gene categories associated with cell death by ToRSV.}

The most striking and unique symptom caused by ToRSV was the appearance of generalized necrosis and cell death in systemically infected tissues. Cell death can be stimulated by a wide range of inducers and generally is believed to result from several distinct but likely overlapping cellular-mediated pathways, collectively referred to as programmed cell death (PCD) (Broker et al. 2005). Among these are apoptotic pathways mediated by caspases or the mitochondria, nonapoptotic necrosis, and autophagy. These different forms of PCD share a number of features, including degradation of proteins, macromolecules and cellular organelles, changes in membranes, vesicle trafficking, cytoskeletal architecture, activation or release of proteases into the cytosol, and loss of mitochondrial membrane potential (Broker et al. 2005). Although the cause of necrosis in ToRSV infected plants is not known, three gene categories with known connections to PCD were uniquely induced by ToRSV. These include energy/mitochondria, membrane/cytoskeleton/intracellular transport, and proteolysis/proteasome. Although these gene categories cannot be linked unequivocally to the observed necrosis, the fact that they were not significantly induced by viruses which did not cause PCD supports this notion.

\section{Summary.}

By comparing changes in host gene expression caused by distinct viruses, it was possible to draw some general parallels with observed symptomology and known cytopathic effects. At 2 weeks PI, ToRSV displayed symptoms of chlorosis, necrosis, and wilting. Consistent with these symptoms, genes associated with chloroplast function were repressed; stress- or pathogenesis-related genes, including water-deficit response genes, were induced; and gene categories associated with cell death were induced. PPV caused chlorosis and changes in leaf morphology. Known cytopathic effects of PPV include formation of distinct inclusions bodies, evaginations of chloroplast and nuclear membranes, and increased nucleoprotein synthesis and numbers of ribosomes (Brunt et al. 1997; Rankovic 1974). PPV repressed the expression of chloroplast-associated genes, induced stress- or pathogenesis-related genes, and induced expression of cytoplasmic ribosomal subunits. PNRSV caused little symptomology and likewise few gene expression changes. Collectively, these data reveal that comparative gene expression profiling has the potential to reveal connections between gene expression changes and associated symptoms. In the future, expanded studies that encompass more viruses with varying symptomology, multiple time points after infection, and multiple tissue types, developmental stages, and disease states will delineate a more comprehensive view of these host transcriptional changes associated with specific symptoms in both time and space.

\section{MATERIALS AND METHODS}

\section{Plants and virus inoculations.}

Because PPV is a quarantined pathogen, inoculations with all three viruses were conducted in the BSL3 greenhouse facility at the United States Department of Agriculture-Agricultural 
Research Service (USDA-ARS), Foreign Disease-Weed Science Research Unit, Fort Detrick, MD, U.S.A. Three-week-old greenhouse-grown $N$. benthamiana plants were inoculated by rubbing plant sap infected with PPV (D-type, PENN1 strain), ToRSV (peach yellow bud mosaic strain), or PNRSV (undefined Prunus strain) onto two fully expanded leaves dusted with Carborundum. Eight plants were inoculated with each virus or mock inoculated using sap from healthy plants. All 32 plants were randomized and maintained in the same growth chamber at $22^{\circ} \mathrm{C}$ for 14 days. This experiment was repeated twice. Four biological replicates derived from two virus-infected plants from each replica experiment (four plants total) were used for hybridizations. RNA from all mock-inoculated plants was similarly pooled to create four biological replicates. Each replicate control served as a universal reference sample that was hybridized to one of the four biological replicates from each of the three virus treatments. Dye swaps were performed on all four biological replicates. Therefore, data for each virus was derived from eight hybridizations with the exception of ToRSV, in which case one dye flip was unsuccessful and data only collected for only seven hybridizations.

\section{RNA extraction.}

After 14 days, uninoculated systemic leaves displaying symptoms or similar-aged healthy leaves from mock-inoculated controls were harvested and immediately frozen in liquid $\mathrm{N}_{2}$. Total RNA was purified using Trizol (Invitrogen, Carlsbad, CA, U.S.A.) according to a modified protocol. RNA subsequently was treated with Turbo RNase-free DNase (Ambion, Austin, TX, U.S.A.) according to the manufacturer's instructions. Finally, total RNA was further purified on RNeasy midiprep columns (Qiagen, Valencia, CA, U.S.A.) and quantified using a Nanodrop (Wilmington, DE, U.S.A.) spectrophotometer. RNA was prepared using this same protocol for both microarray and real-time PCR experiments.

\section{cDNA labeling and microarray hybridization.}

All labeling and hybridization experiments were carried out by The Institute for Genomic Research (TIGR), Rockville MD, U.S.A. Labeled cDNA was derived from $20 \mu \mathrm{g}$ of total RNA was indirectly labeled with $\mathrm{Cy} 3$ or $\mathrm{Cy} 5$. Complete protocol descriptions and detailed protocols for microarray hybridization are available online.

\section{Data analysis.}

Microarray scanning, spot finding, and raw data collection were performed by TIGR. Detailed quantification and normalization as well as spot finding methods are available online. All microarray images, expression data, and detailed experimental descriptions are available at the TIGR potato functional genomics website under ID number 88 . Normalization and expression significance analysis was performed using the commercially available GeneSpring software (Silicon Genetics, Redwood City, CA, U.S.A.). Mean normalized expression values for each gene were calculated from data derived from eight scanned microarray images (four biological replicates and four dye swaps) for each virus treatment. Genes showing statistically significant changes in response to infection by PPV, ToRSV, and PNRSV were identified using $P$ value assignments $<0.05$ derived from one-way analysis of variance analysis followed by multiple testing correction of Benjamini and Hochberg (<0.05) (Benjamini and Hochberg 1995).

\section{Gene categorization.}

First, the application Blast2Go (Conesa et al. 2005) was used to complement existing potato gene annotation. Second, gene annotation was further supplemented with manual
BLASTX, conserved domains, and literature searches. Keywords derived from published literature and National Center for Biotechnology Information entry data were added to each gene. Using this combined information, a functionally driven classification scheme (based in part on GO classes), comprising 23 categories, was created manually. Larger categories were further subdivided into subcategories. Some of these were created to reflect the biology of interest such as auxinrelated, RNA silencing, and virus interaction, all of which have known connections to virus pathogenesis. In many instances, individual genes fell into more than one category and deciding where each gene belonged was problematic. Therefore, a secondary classification was performed for three categories (chloroplast function/photosynthesis, stress/pathogenesis, and virus interaction) to capture all related genes that initially were classified into different primary categories.

Significance tests were performed on all categories and subcategories for each virus; $\chi^{2}$ tests were used for those containing $>50$ genes whereas Fisher's exact test was used for those containing $<50$ but $>10$ genes. Expected values were calculated based on the ratio of all induced versus repressed statistically significant genes for each virus. Two categories with largely random assignments, including "unknown" and "transcription factor/unknown," served as negative controls and, as expected, were not identified as statistically significant.

\section{Real-time PCR.}

Reactions were performed in the ABI Prism 7900HT sequence detector (Applied Biosystems, Foster City, CA, U.S.A.). The real-time assay was performed using SuperScript III Platinum SYBR Green One-Step qRT-PCR Kit (Invitrogen). The qRT-PCR reagent $(13 \mu \mathrm{l})$ was added to $2 \mu \mathrm{l}$ of total RNA. The $15-\mu$ assay contained $1 \times$ SYBR Green reaction mix (includes $0.2 \mathrm{mM}$ each $\mathrm{dNTP}$ and $3 \mathrm{mM} \mathrm{MgSO} 4$ ), $200 \mathrm{nM}$ each forward primer $\left(5^{\prime}\right)$ and reverse primer $\left(5^{\prime}\right)$, and $500 \mathrm{nM}$ Rox reference dye. Rox was used as a passive dye for assay volume normalization. qRT-PCR was carried out at $50^{\circ} \mathrm{C}$ for 5 $\min , 95^{\circ} \mathrm{C}$ for $5 \mathrm{~min}$, and 40 cycles of $95^{\circ} \mathrm{C}$ for $15 \mathrm{~s}$ and $60^{\circ} \mathrm{C}$ for $30 \mathrm{sec}$. A final denaturation step was included to verify the amplification of a single PCR product for each reaction. PCR product size was verified by agarose gel electrophoresis of amplified products (data not shown). Threshold cycle values were obtained from the ABI 7900 Sequence Detection software (Applied Biosystems). Linearity over the 20- to 40-cycle range was established by standard dilution curves. All reactions were done in triplicate and the values averaged. Two RNA concentrations, 5 and $50 \mu \mathrm{g}$, were used for all experimental samples. Data falling closest to the standard curve was reported. Constitutively expressed control genes used for normalization were identified from the microarray data. Five genes were identified as highly constitutive across all virus treatments and one (STMGG19) was chosen based on efficient and consistent PCR amplification (data not shown). STMGG19 was used to normalize all real-time PCR data derived from all RNA samples.

\section{ACKNOWLEDGMENTS}

A number of individuals assisted with the experiments and data analysis described in this manuscript. E. Lutton (USDA-ARS, Appalachian Fruit Research Station, Kearneysville, WV, U.S.A.) performed RNA extractions and real-time PCR experiments. A. Stone, V. Damsteegt, and W. Schneider (USDA-ARS, Fort Detrick, MD, U.S.A.) propagated and maintained N. benthamiana plants and provided BSL-3 greenhouse and growth chamber space required for PPV work. M. Ragupathy (Agriculture and Agri-Food Canada, London, Ontario, Canada) provided valuable guidance and assistance with microarray data analysis. Potato arrays, hybridization services, and raw data analyses were generously provided by The Institute for Genomic Research (Rockville MD, U.S.A.) with funding from the National Science Foundation 
(DBI-9975866 and DBI-0218166). I thank T. Omura (National Agricultural Research Center, Tsukuba, Japan) for kindly providing me with a copy of their manuscript prior to publication. I also would like to thank R. Scorza, A. Callahan, and Z. Liu (USDA-ARS, Appalachian Fruit Research Station) for their critical reading of the manuscript.

\section{LITERATURE CITED}

Abbink, T. E., Peart, J. R., Mos, T. N., Baulcombe, D. C., Bol, J. F., and Linthorst, H .J. 2002. Silencing of a gene encoding a protein component of the oxygen-evolving complex of photosystem II enhances virus replication in plants. Virology 295:307-319.

Atkinson, P. H., and R. E. Matthews. 1970. On the origin of dark green tissue in tobacco leaves infected with tobacco mosaic virus. Virology 40:344-356.

Balachandran, S., Hull, R. J., Vaadia, Y., Wolf, S., and Lucas, W. J. 1995. Alteration of carbon partitioning induced by the movement protein of tobacco mosaic virus originates in the mesophyll and is independent of change in the plasmodesmal size exclusion limit. Plant Cell Environ. 18:1301-1310.

Balasubramaniama, M., Ibrahima, A., Kima, B. S., and Sue Loesch-Fries, L. 2006. Arabidopsis thaliana is an asymptomatic host of Alfalfa mosaic virus. Virus Res. 121:215-219.

Barakat, A., Szick-Miranda, K., Chang, I. F., Guyot, R., Blanc, R., Cooke, R., Delseny, M., and Bailey-Serres, J. 2001. The organization of cytoplasmic ribosomal protein genes in the Arabidopsis genome. Plant Physiol. 127:398-415.

Beck, F. C. 2005. Signaling pathways from the chloroplast to the nucleus. Planta 222:743-756.

Benjamini, Y., and Hochberg, Y. 1995. Controlling the false discovery rate: a practical and powerful approach to multiple testing. J. R. Stat. Soc. Ser. B 57:289-300.

Biehl, A., Richly, E., Noutsos, C., Salamini, F., and Leister D. 2005 Analysis of 101 nuclear transcriptomes reveals 23 distinct regulons and their relationship to metabolism, chromosomal gene distribution and co-ordination of nuclear and plastid gene expression. Gene 344:33-41.

Biemelt, S., and Sonnewald U. 2006. Plant-microbe interactions to probe regulation of plant carbon metabolism. J. Plant Physiol. 63:307-318.

Broker, L. E., Kruyt, F. A. E., and Giaccone, G. 2005. Cell death independent of caspases: a review. Clin. Cancer Res. 11:3155-3162.

Brunt, A. A., Crabtree, K., Dallwitz, M. J., Gibbs, A. J., Watson, L., and Zurcher, E. J., eds. 1997. Plant Viruses Online: Descriptions and Lists from the VIDE Database. Version: 16th January 1997. Published online.

Carrington, J. C., Jensen, P. E., and Schaad, M. C. 1998. Genetic evidence for an essential role for potyvirus CI protein in cell-to-cell movement. Plant J. 14:393-400.

Chang, I. F., Szick-Miranda, K., Pan, S., and Bailey-Serres, J. 2005. Proteomic characterization of evolutionarily conserved and variable proteins of Arabidopsis cytosolic ribosomes. Plant Physiol. 137:848-862.

Chen, W., Provart, N., Glazebrook, J., Katagiri, F., Chang, H. S., Eulgem, T., Mauch, F., Luan, S., Zou, G., Whitham, S. A., Budworth, P. R., Tao, Y., Xie, Z., Chen, X., Lam, S., Kreps, J. A., Harper, J., Si-Ammour, A., Mauch-Mani, B., Heinlein, M., Kobayashi, K., Hohn, T., Dangl, J. L., Wang, X., and Zhu, T. 2002. Expression profile matrix of Arabidopsis transcription factor genes implies their putative functions in response to environmental stresses. Plant Cell 14:559-574.

Choi, D., Kim, H. M., Yun, H. K., Park, J. A., Kim, W. T., and Bok, S. H. 1996. Molecular cloning of a metallothionein-like gene from Nicotiana glutinosa L. and its induction by wounding and Tobacco mosaic virus infection. Plant Physiol. 112:353-359.

Conesa, A., Gotz, S., Garcia-Gomez, J. M., Terol, J., Talon, M., and Robles, M. 2005. Blast2GO: A universal tool for annotation, visualization and analysis in functional genomics research. Bioinformatics 21:3674-3676.

Dardick, C. D., Golem, S., and Culver, J. N. 2000. Susceptibility and symptom development in Arabidopsis thaliana to Tobacco mosaic virus is influenced by virus cell to cell movement. Mol. Plant-Microbe Interact. 13:1139-1144.

Decroocq, V., Sicard, O., Alamillo J. M., Lansac, M., Eyquard, J. P., García, J. A., Candresse, T., Le Gall O., and Revers, F. 2006. Multiple resistance traits control Plum pox virus infection in Arabidopsis thaliana. Mol. Plant-Microbe Interact. 19:541-549.

Fu, D. Y., Hong, J., Chen, J. S., and Wu, J. X. 2004. Accumulation of coat protein of Turnip mosaic virus in host chloroplasts and its effect on PS II activity. J. Plant Physiol. Mol. Biol. 30:34-40. (In Chinese)

Golem, S., and Culver, J. N. 2003. Tobacco mosaic virus induced alterations in the gene expression profile of Arabidopsis thaliana. Mol. PlantMicrobe Interact. 16:681-688.

Havelda, Z., and Maule, A. J. 2000. Complex spatial responses to Cucum- ber mosaic virus infection in susceptible Cucurbita pepo cotyledons. Plant Cell 12:1975-1986.

Herbers, K., Tacke, E., Hazirezaei, M., Krause, K. P., Melzer, M., Rohde, W., and Sonnewald, U. 1997. Expression of a luteoviral movement protein in transgenic plants leads to carbohydrate accumulation and reduced photosynthetic capacity in source leaves. Plant J. 12:1045-1056.

Huang, Z., Yeakley, J. M., Garcia, E. W., Holdridge, J. D., Fan, J. B., and Whitham, S. A. 2005. Salicylic acid-dependent expression of host genes in compatible Arabidopsis virus interactions. Plant Physiol. 137:11471159.

Jameson, P. E., and Clarke, S. F. 2002. Hormone-virus interactions in plants. CRC Crit. Rev. Plant Sci. 21:205-228.

Jimenez, I., Lopez, L., Alamillo, J. M., Valli, A., and Garcia, J. A. 2006. Identification of a Plum pox virus CI-interacting protein from chloroplast that has a negative effect in virus infection. Mol. Plant-Microbe Interact. 19:350-358.

Kasschau, K. D., Xie, Z., Allen, E., Llave, C., Chapman, E. J., Krizan, K. A., and Carrington, J. C. 2003. P1/HC-Pro, a viral suppressor of RNA silencing, interferes with Arabidopsis development and miRNA function. Dev. Cell. 4:205-217.

Kasuga, T., Townsend, J. P., Tian, C., Gilbert, L. B., Mannhaupt, G., Taylor, J. W., and Glass, N. L. 2005. Long-oligomer microarray profiling in Neurospora crassa reveals the transcriptional program underlying biochemical and physiological events of conidial germination. Nucleic Acids Res. 33:6469-6485.

Kleffmann, T., Russenberger, D., von Zychlinski, A., Christopher, W., Sjolander, K., Gruissem, W., and Baginsky, S. 2004. The Arabidopsis thaliana chloroplast proteome reveals pathway abundance and novel protein functions. Curr. Biol. 14:354-362.

Kong, L. J., Orozco, M., Roe, J. L., Nagar, S., Ou, S., Feiler, H. S., Durfee, T., Miller, A. B., Gruissem, W., Robertson, D., and Hanley-Bowdoin, L. 2000. A geminvirus replication protein interacts with the retinoblastoma protein through a novel domain to determine symptoms and tissue specificity of infection in plants. EMBO (Eur. Mol. Biol. Organ.) J. 19:3485-3495.

Mahajan, S., Chisholm, S., Whitham, S., and Carrington, J. 1998. Identification and characterization of a locus (RTM1) that restricts long-distance movement of tobacco etch virus in Arabidopsis thaliana. Plant J. 14:177-186.

Marathe, R., Guan, Z., Anandalakshmi, R., Zhao, H., and Dinesh-Kumar, S. P. 2004. Study of Arabidopsis thaliana resistome in response to $\mathrm{Cu}$ cumber mosaic virus infection using whole genome microarray. Plant Mol. Biol. 55:501-520.

Mathews, R. E. F. 1991. Plant Virology, 3rd ed. Hartcourt Brace, Javonovich, San Diego, CA, U.S.A.

Mauch, F., Mauch-Mani, B., Gaille, C., Kull, B., Haas, D., and Reimmann, C. 2001. Manipulation of salicylate content in Arabidopsis thaliana by the expression of an engineered bacterial salicylate synthase. Plant J. 25:67-77.

Minoiu, N. 2002. Electron-microscopic changes in the ultra-structures of the plum tree leaves caused by Plum pox virus. Sanatatea plantelor, Plant Health July:45-47.

Nakao, A., Yoshihama, M., and Kenmochi, N. 2004. RPG: the ribosomal protein gene database. Nucleic Acids Res. 32:168-170.

Padmanabhan, M. S., Goregaoker, S. P., Golem, S., Shiferaw, H., and Culver, J. N. 2005. Interaction of the Tobacco mosaic virus replicase protein with the Aux/IAA protein PAP1/IAA26 is associated with disease development. J. Virol. 79:2549-2558.

Padmanabhan, M. S., Shiferaw, H., and Culver, J. N. 2006. The Tobacco mosaic virus replicase protein disrupts the localization and function of interacting Aux/IAA proteins. Mol. Plant-Microbe Interact. 19:864-873.

Rankovic, M. 1974. Purification of sharka virus and characteristics of the purified isolates. Ph.D. thesis. University of Belgrade, Yugoslavia.

Rensink, W. A., Lee, Y., Liu, J., Iobst, S., Ouyang, S., and Buell, C. R. 2005. Comparative analyses of six solanaceous transcriptomes reveal a high degree of sequence conservation and species-specific transcripts. BMC Genomics 6:124.

Rojas, M. R., Zerbini, F. M., Allison, R. F., Gilbertson, R. L., and Lucas, W. J. 1997. Capsid protein and helper component-proteinase function as potyvirus cell-to-cell movement proteins. Virology 237:283-95.

Sato, S., Nakamura, Y., Kaneko, T., Asamizu, E., and Tabata S. 1999. Complete structure of the chloroplast genome of Arabidopsis thaliana. DNA Res. 29:283-290.

Schmid, J., and Amrhein, N. 1995. Molecular organization of the shikimate pathway in higher plants. Phytochemistry 39:737-749.

Senthil, G., Liu, H., Puram, V. G., Clark, A., Stromberg, A., and Goodin, M. M. 2005. Specific and common changes in Nicotiana benthamiana gene expression in response to infection by enveloped viruses. J. Gen. Virol. 86:2615-2625.

Shimizu, T., Satoh, K., Kikuchi, S., and Omura, T. The repression of cell 
wall- and plastid-related genes and the induction of defense-related genes in rice plants infected with Rice dwarf virus. Mol. Plant-Microbe Interact. 3:247-254

Simon, A. E., Li, X. H., Lew, J. E., Stange, R., Zhang, C., Polacco, M., and Carpenter, C. D. 1992. Susceptibility and resistance of Arabidopsis thaliana to turnip crinkle virus. Mol. Plant-Microbe Interact. 5:496503.

Trinks, D., Rajeswaran, R., Shivaprasad, P. V., Akbergenov, R., Oakeley, E. J., Veluthambi, K., Hohn, T., and Pooggin, M. M. 2005. Suppression of RNA silencing by a geminivirus nuclear protein, AC2, correlates with transactivation of host genes. J. Virol. 79:2517-2527.

Wade, C. H., Umbarger, M. A., and McAlear, M. A. 2006. The budding yeast rRNA and ribosome biosynthesis (RRB) regulon contains over 200 genes. Yeast 23:293-306.

Wasternack, C., Stenzel, I., Hause, B., Hause, G., Kutter, C., Maucher, H., Neumerkel, J., Feussner, I., and Miersch O. 2006. The wound response in tomato-role of jasmonic acid. J. Plant Physiol. 163:297-306.

Whitham, S. A., Quan, S., Chang, H. S., Cooper, B., Estes, B., Zhu, T., Wang, X., and Hou, Y. M. 2003. Diverse RNA viruses elicit the expression of common sets of genes in susceptible Arabidopsis thaliana plants. Plant J. 33:271-283.
Whitham, S. A., Yang, C., and Goodin, M. 2006. Global impact: elucidating plant responses to viral infection. Mol. Plant-Microbe Interact. 19:1207-1215.

Xie, Z., B. Fan, C. Chen, and Z. Chen. 2001. An important role of an inducible RNA dependent RNA polymerase in plant antiviral defense. Proc. Natl. Acad. Sci. U.S.A. 98:6516-6521.

Zhu, S., Gao, F., Cao, X., Chen, M., Ye, G., Wei, C., and Li, Y. 2005. The Rice dwarf virus $\mathrm{P} 2$ protein interacts with ent-kaurene oxidases in vivo, leading to reduced biosynthesis of gibberellins and rice dwarf symptoms. Plant Physiol. 139:1935-1945.

\section{AUTHOR-RECOMMENDED INTERNET RESOURCES}

Rothamsted Research: www.rothamsted.ac.uk

The Institute for Genomic Research (TIGR) functional genomics potato array website: www.tigr.org/tdb/potato/microarray_desc.shtml

TIGR protocols:

www.tigr.org/tdb/potato/images/SGED_SOP_3.1.1.pdf www.tigr.org/tdb/potato/images/SGED_SOP_5.2.1.pdf www.tigr.org/tdb/potato/images/SGED_SOP_6.2.4.pdf 